\title{
Representational Practices in Demands Driven Development of Public Sector
}

\author{
Johanna Sefyrin $^{1}$, Katarina L Gidlund ${ }^{1}$, Karin Danielsson Öberg ${ }^{2}$, \\ and Annelie Ekelin ${ }^{3}$ \\ ${ }^{1}$ Mid Sweden University, Sundsvall, Sweden \\ \{johanna.sefyrin, katarina. lindblad-gidlund\} @miun. se \\ ${ }^{2}$ Umeå University, Umeå, Sweden \\ kdson@informatik.umu.se \\ ${ }^{3}$ Linnæus University, Kalmar, Sweden \\ annelie.ekelin@lnu.se
}

\begin{abstract}
This paper concerns representational practices in demands driven development of public sector, and the problems they involve. The term demands driven development refers to a movement in public sector towards a closer cooperation with the citizens, primarily with regards to the development of public e-services. The objective with the paper is to explore representational practices through the analysis of practitioners' talk about demands driven development. There are several interrelated problems with representational practices, in this paper analysed through the discussions of practitioners who work with demands driven development of public sector. The conclusion is that these practitioners work with representational practices in a way which they at the same time seem to consider rather problematic.
\end{abstract}

Keywords: demands driven development, public sector, e-services, representationalism, feminist theory.

\section{Introduction}

This paper concerns representational practices in demands driven development of public sector, and the problems they involve. The term demands driven development refers to a movement in public sector towards a closer cooperation with the citizens, primarily with regards to the development of public e-services. This development currently takes place in Sweden as well as in other countries [15, 4]. The expected benefit of a closer cooperation with citizens is to make public sector more efficient and thus minimize public costs [4]. It is supposed that if the citizens are somehow involved in the development of these services, they will also be more inclined to use them [4]. Our objective is to explore representational practices through the analysis of practitioners' talk about demands driven development. There are several interrelated problems with representational practices; one is that they invoke questions of truthfulness, in terms for instance if a person really can represent a group of other persons $[1,2]$. Second, categories open to representation are heterogeneous and multifaceted, 
thus making it problematic to talk about for instance 'women'. Third, categories are produced within existing dominant power relations [2]. Fourth, some are defined as inside the available categories whilst others fall outside, and some might not fit into any category and hence become invisible [3]. We will get back to these problems and discuss them more in depth in the following sections of the paper. Our main focus in the paper is to problematize representationalism in demands driven development, not to explore alternatives.

The question of who participates in participatory public projects such as demands driven development, and on what grounds, determines much of the legitimacy for these projects in the wider democratic system [12]. In the Swedish guidelines for demands driven development, it is stated that "A difficult question is how to find users who are representative for a target group and whose demands and wishes covers the demands of the whole target group. Additionally asking everybody is too costly. The point of departure should be that it is always better to have asked some than not to have asked at all. One does not get a comprehensive image of the demands, but at least some general demands can be found" [5:20]. Consequently the demands that are enunciated in demands driven development projects will depend very much on these users, whether they are representative of other users or not. The issue of representation is obviously central here, but in what sense is it possible for these participating citizens to be representative for someone else?

The paper is structured as follows: first the theoretical points of departure are presented, followed by a presentation of the research project. After that the research approach is described and after that the practitioners' talk about representation in demands driven development is analyzed. The paper is concluded with a discussion of the analysis.

\section{Theoretical Points of Departure}

The feminist science and technology studies (STS) scholar Karen Barad [1] argues that the idea of autonomous preexisting objects and subjects with inherent attributes lies behind the problems with representational practices, political as well as linguistic and epistemological. In her view representationalism is the idea that there exist two kinds of entities; first of all reality or real entities that can be represented, and second (mental or cognitive) representations of those entities. In a representationalist world view these are understood as separated and thus independent of each other. Sometimes a third party is included; someone who does the representing (an individual). Barad underscores that the problem is that entities - subjects, objects, various categories and so forth - are understood as autonomous from and unaffected by practices of representing. In such an individualist metaphysics gender, ethnicity, age, sexuality and class are understood as rather static properties located in individuals, which thus are possible to represent [1]. Judith Butler, another feminist science scholar [2], makes a similar analysis and argues that the (feminist) subject - 'women' - is not homogeneous, and furthermore does not simply exist as an independent being, waiting to be represented, but is rather produced by the discursive practices and structures 
that are supposedly doing the representing. With such an analysis, an independent subject does not exist, but subjects are instead produced by the practices of which they are part, including the practices which purport to do the representing (more about this below). This argument is based on a constructivist point of departure in which practices such as representing not only describes an independently existing world, but also (re)produces the world. For instance in demands driven development projects in public sector groups of citizens are chosen as important. In this process several practices contribute to constructing these citizens as specific citizens, such as how these groups are defined and described - women, adolescents, immigrants, parents, elderly, students who are parents - how they are distinguished from other groups of citizens (for instance what defines an immigrant as opposed to a Swede?), on what grounds the demands of a specific group are important in a specific development project, and the conditions under which these citizens are allowed to formulate demands.

Representationalism causes several major and interrelated problems. The first of these is that since reality or the entities therein are not identical to the representations, the question of the truthfulness of these representations becomes central. Representations are supposed to work as a mediator between separately existing entities - that is, between entities in reality, and the person who does the representing. This generates questions of the correspondence between reality and the representations. For instance, can a person who participates in demands driven development accurately represent a whole group of individuals, for instance mothers [1]?

Second, categories of subjects and objects are not homogeneous, but categories such as women, men, Swedes, immigrants, adolescents and heterosexuals consist of a number of heterogeneous subjects. The problem is that when someone talks about women it is hard to know what this means, that is, what kind of woman this refers to, since women come in many forms - old, young, heterosexual, lesbian, middle class, working class, single, in relations, white, black and so forth. Talk about women furthermore indicates that women would be alike, when this is not the case [2].

Third, subjects and objects are produced by the practices, discourses and structures of which they are part $[1,2,8]$. Consequently there are no detached or independent entities which can be represented, and there are no independent entities which can do the representing, but instead these subjects and objects are produced by a variety of representational practices. Through these practices power is exercised, i.e. exclusionary practices of power are exercised in order to define what is being represented. For instance when a child is born in Sweden, and if the parents are heterosexual and married it is assumed that the man who is married to the child's mother also is the father, while if the man is not married to the mother but they 'only' live together, a fatherhood inquiry is conducted by the municipality in which the parents live. In other words legislative and administrative practices contribute to constructing fatherhood as self-evident only as long as the parents are married and heterosexual.

Fourth, this means that the categories that are available for representation are formed within dominant practices and power relations, through the performance of boundaries that include and exclude. This recognition places questions of who are included in the category of women, who fall outside, and who does not fit into any category at the center of attention $[2,3]$. The above example about fatherhood also 
exemplifies how legislative and administrative practices reproduce specific family norms, and thus contribute to marginalize other family configurations - such as same sex and single parent families.

\subsection{Posthumanist Alternatives to Individualism}

The alternative to representationalism is to focus not on preexisting subjects and objects, but on how these entities are produced in practices, something which many feminist scholars have focused on. Donna Haraway [10:328] writes: "Gender is a verb, not a noun. Gender is always about the production of subjects in relation to other subjects, and in relation to artifacts. Gender is about material-semiotic production of these assemblages, these human-artifact assemblages that are people. People are always already in assemblage with the world" Many of these researchers have extended the argument also to other identity formations such as sexuality [2, 3], class [19], ethnicity [7], religion [ibid.], and age [16]. This kind of research emphasizes how these practices are fundamentally entangled, and how they both enable and constrain specific subject formations. With such a point of departure gender - and other identity formations - should not be understood as individual traits which causes specific gendered doings, but instead gendered subject emerges or materializes as a result of specific performances and enactments. The construction of subjects is not done once and for all, but is rather an ongoing process of materialization which produce subjects, and of which subjects are parts. Butler [3] argues that the construction of sex as materiality is not done once and for all, but is in itself a process located in time, a kind of temporal unfolding or becoming, which works through the reiteration of norms. For the purposes of this paper we extend the argument to include not only the materialization of bodily formations, but also other identity formations, and understand subjects as a process of constant unfolding, that is, as something that is never set or fixed. With this view subjects are continuously evolving sociomaterial configurations of a variety of identity producing sociomaterial practices, which constantly vary and change. Identity producing sociomaterial practices are for instance linguistic and semiotic practices of talking, writing, and imaging, but also legislative practices of defining specific groups such as laws against discrimination.

This displacement from pre-given subjects and objects, to entities as the result and part of intra-acting sociomaterial practices has several implications related to the problems with representationalism mentioned above. Obviously the existence of subjects and objects cannot be taken for granted, but instead they are produced, reproduced and reconfigured in each new situation, as the sociomaterial practices of which they are part change. For representational practices this means that categories cannot be taken for granted, but must be construed anew, as locally situated, contingent and temporary categories, in each new situation.

\subsection{Alternative Practices?}

The previous discussion about how identity formations such as gender, age, ethnicity, and class should be understood as results and parts of ongoing productive materialdiscursive practices has several implications for demands driven development. First of 
all, it becomes virtually impossible to represent anyone else, that is, a category of subjects such as women, on the basis that subjects are intersections (or configurations) of a variety of identity producing practices, which are constantly reconfigured. Second, in other words, it is practically impossible to configure stable and coherent categories, since subjects are fluid and volatile, and consequently categories based on some sort of subject formation(s) would be unstable and differentiated. If someone would consciously try to represent a category of subjects - such as colleagues on a department - the result would be a representation of what that subject believes about the category, and thus based on prejudices. The consequence is that a subject can only participate in demands driven development as her (temporary) self, who could be similar with others in a similar position, but this cannot be taken for granted. Furthermore, based on how categories are formed within dominant material-discursive practices, and how there always is a risk that some individuals fall outside of categories, actors working with demands driven development would have to be very careful with how categories are constructed. From the above follows that it becomes impossible to use preexisting and generic categories of subjects, such as the common demographic categories mentioned (gender, age, ethnicity, and class).

\section{The Research Project}

This paper is written within the frame of a now finished project about demands driven development of public sector, conducted in Sweden. The overall project objective was to deepen the understanding of demands driven development processes in public sector from the perspectives of organizational culture and design methods. The project lasted for a year, and was run by four researchers situated at three different and geographically dispersed universities in Sweden. Furthermore a group of about thirty practitioners working in Swedish government agencies were involved in the project as key actors. These practitioners were women and men with different job descriptions, experiences and educational backgrounds, but they all worked with and were responsible for the implementation of demands driven development of public sector in their respective organizations. This project can be understood as the continuation of an earlier project with a similar research focus [14]; two of the researchers and all of the practitioners took part in this earlier project. Within the project empirical material was gathered in several ways, such as through surveys, interviews and workshops with the practitioners, but policy documents were also used. Workshops with the practitioners constituted a central activity in the project; totally five workshops were arranged in Stockholm. These workshops had different themes, all based on the suggestions of the practitioners: representativity, accessibility, crowd sourcing, scenario based decision making, and critical design. Most parts of the workshops were filmed by a media specialist who also took part in the project. The workshops had the following structure; they took place between 9.30 and 15.00, and included a lecture of one or more invited speaker(s) (a researcher and/or a practitioner) who talked about the current topic. Furthermore the topic was treated through assignments in smaller groups, and discussions in the whole group. 


\section{Methodological Approach}

The project was developed in rather close relation to the practitioners, who had chosen topics for four of the five workshop themes, and the objective was to develop new knowledge in close cooperation between researchers and practitioners. The first workshop considered representativity in demands driven design. Seven practitioners from various government agencies participated in the workshop. During the workshop an invited researcher in political science was giving a lecture about representational issues and recruitment strategies. This topic was discussed in the whole group, and the participants were also divided into two focus groups that were asked to discuss representation in relation to the recruitment strategies used in their own organizations. The participants in these focus groups were asked to do a SWOT (Strengths, Weaknesses, Opportunities, Threats) analysis of the recruitment strategies they practiced. This means that even though the topic of representation was initiated by the practitioners, the researchers developed and expanded this topic in a specific way. Consequently, the talk that is analyzed below is far from spontaneous talk, but instead it can be understood as - at least in part - the result of the survey and the lecture about representational issues.

The empirical material that is the basis for this paper consists of notes and recorded and transcribed group discussions from the workshop, while results from the survey are used only briefly. The practitioners and the government agencies in which they work are anonymized in the paper. This material was analyzed with the help of the theoretical framework described above, in which the problems with representationalism is said to consist of four different but interrelated parts; first of all representational practices raise questions of truthfulness, in terms for instance if a person really can represent a group of other persons. Second, categories are heterogeneous rather than homogeneous. Third, categories are produced within existing dominant power relations, including representational practices. Fourth, since categories are the result of boundary making, some are defined as inside existing categories whilst others fall outside, and some might not fit into any category and are hence become invisible. If these are translated into the context of demands driven development the issue of truthfulness concerns whether a specific person or group do or can represent someone else, like a (larger) group. The issue of heterogeneous categories concerns how groups of individuals are heterogeneous rather than homogeneous. The issue of how categories are produced within existing power relation, concerns how categories of persons are made, and by whom. Finally the issue of whether some falls outside of existing categories concerns whether some individuals are forgotten or not included.

These four issues of representation are used as an analytical framework, in order to explore how the practitioners talked about these issues during the workshop, something which indicates how they are understood and handled. However, that they talk about representation in a specific way does not necessarily mean that this is also how they do in their daily work practices. In other words we searched for how instances of these four representational issues turned up in the notes and the transcriptions of the discussions. Furthermore we searched the survey results for indications of how representational problems were understood and handled. 


\section{Representational Practices in Demands Driven Development}

The survey result indicates that the practices for working with demands driven development, that is, for involving citizens in the development of various e-services, are very different. Some work with personas ${ }^{1}$, some work with so called behavioral groups, some have established networks of clients which they cooperate with, some work with focus groups, and some are happy just to find any participants for their development projects. Based on these different practices, representationalist problematic becomes very different. Below a number of citations from the transcribed group discussions, and from notes taken during the workshop about representations are presented. These citations are selected because they in some sense touched upon the topics described in the analytical framework; the issue of truthfulness of representations, the issue of heterogeneous groups, the issue of how categories available for representations are produced within various power relations, and the issue of how some are excluded from available categories, and thus become invisible.

\subsection{The Issue of Truthfulness}

A. ... that's how we use to do when we have specific services that are aimed at [a specific group of users] ... then we chose among those who are professional users of a service, then we chose those who are large, who have very many cases ... those who are in between and those who do not use it at all in order to get the whole perspective ... (from transcriptions)

In this first example one of the practitioners discussed how they in her organization use to choose participants when they work with the development of a specific service. Their clients are businesses of different sizes, and so the users are working in and with those businesses. Thus they use to select among these the businesses that are large and use the service very much, the businesses who use the service sometimes, and those who do not use the service at all. This indicates that they try to select users for their development projects in order to reach a specific representativeness - or in other words in accordance with the use patterns of the whole group. The strategy for achieving accordance with this heterogeneous group is to try to find users who represent the extremes and the medium of businesses; those who are frequent users, those who are medium frequent users, and those who are non-users of the service.

B. ... if I would say like this: "Now I turn to you because you are a larger representative who work with agency 2 , now I want you to put on a general representation hat". Then they would not be interested ... then you chose a few [representatives] and you get a more nuanced picture ... but not that ... one would try to say that you are here as a representative and not from your own parts [e.g. department or organization], not that you should try to put on the whole guild's... (from transcriptions)

Personas are hypothetical users [18]. 
Our interpretation is that the practitioner here discussed how some of the potential participants in the development projects run by her organization would not be interested if she would ask them to participate as representatives of their professional society (or guild). The practitioner believed they would only want to participate if they could represent themselves, and pursue the questions that are interesting for them, but not if they would have to work for their professional colleagues in other organizations. This is an aspect of representation that is related to whether participants want to participate in their own interests or in the whole group's - but the assumption is still that someone can represent a whole group. Nevertheless, with this statement ("now I want you to put on a general representation hat") the practitioner pointed to an indistinctness in representational practices; how is one to know whether someone represents him/herself, and not someone else, like a professional society? Can someone represent both at once? Do they?

The rather frequent occurrence of these and similar enunciations indicates that the practitioners are well aware of the problematic of letting someone speak for or represent an entire group. On the other hand, both group discussions and the result from the survey indicates that several of the practitioners are rather happy to have any participants in their supposedly demands driven development processes ("We are happy to have any [participants]" (from survey)), and in those cases, issues of whether these are representative for an entire group seemed to become subordinate.

\subsection{The Issue of Heterogeneous Categories}

C. Anne: ... well, immigrant women then we might have that group ... perhaps you don't think twice ... kind of like we do now, we talk a little about ... we look at an assignment which concerns people who want to come here and ... from a third country .. it's like a lump, it's like four billion people that can be very heterogeneous ... but we kind of lump them together in that way, I do not know whether it is the right way to lump them... (from transcriptions)

In this quotation one of the practitioners was talking about the problematic practice of lumping large numbers of heterogeneous individuals into one group. The practitioner mentioned immigrant women, and then went on to talking about four billion people from a third country ${ }^{2}$. The practitioner also seemed hesitant to whether this was right, or a good way of lumping these people together ("I do not know whether it is the right way to lump them..."). With this statement this practitioner raised the issue of how groups are heterogeneous, but also how they are produced in practices, and she questioned whether these practices are right. Indirectly the statement thus concerns the power of practices to produce groups, and how this power is used.

2 The term 'third country' refers to countries outside of the European Union (EU), the European Free Trade Association (EFTA), the European Economic Area, and the candidates to the EU (Universitets- och högskolerådet) [20]. 


\subsection{The Issue of How Power Relations Produce Categories}

D. Anne: And the two threats we were talking about was that the one who represent might not understand that $\mathrm{s} / \mathrm{he}$ represents and the other that we might not have been enough clear with that ... have we thought right about this strategic group, or have we chosen someone because "Oh, now we got a woman too, and a man..."

Karin: But wasn't it too that ... I was thinking also that these ... what was it you said here, that you don't understand that you represent something larger, but it might be two different things...

Eva: Yes but sometimes you don't. Then you anyway represent yourself, but I include you, your perspective because you are an immigrant woman, then I include your perspective but you are not expected to talk for everyone... (from transcriptions)

This discussion among the practitioners touched upon several issues relating to how power relations are involved when groups are constructed. Anne talked about how someone might not understand that $\mathrm{s} / \mathrm{he}$ is representing a group, and that this might have to do with that 'we' have not been enough clear with that. 'We' in this case refers to Anne and her colleagues at the agency in which she works, or more generally practitioners working with demands driven development of public sector. Anne also talked about the risk that 'we' have not thought right about a particular group. Our interpretation is that to 'think right' about a group means to construct the group in a way that makes it representative for a larger group. To be able to think right or wrong when constructing groups clearly concerns the power to construct groups, whether the result is considered right or not. Karin responded by talking about the risk that participants do not understand that they represent someone else, like a larger group, while Eva talked about how participants are sometimes included because they belong to a specific group, like immigrant women, even though they are expected to talk only for themselves. Our interpretation is that Eva with this statement raises the issue of how someone is chosen because s/he belongs to a marginalized group - in this case immigrant women - but she nevertheless does not want this immigrant woman to represent anyone else, but only to represent herself. As in previous quotations this refers to the ambiguity for a participant to know whether s/he is supposed to talk for her/himself, or for a larger group. This recurring issue concerns the importance to inform the participants of the expectations of their participation, something which is central to the practitioners because this is part of their responsibilities. This statement also concerns power in terms of how someone is chosen to be included because they supposedly belong to a specific - marginalized - group.

E. Eva: But I think also that perhaps one does not want to ... that one should believe that one represents, that I have chosen you because you represent a Chinese person, but I don't want you to believe that you ... I want you to speak for yourself, I want you to tell your story ... I don't even want you to try to speak for all Chinese ... 
Karin: Because if you do you have yet another source of error when you come to the analysis phase cause then it's not only this person's opinions in the first hand but it's others or his whole imaginary image with prejudice filters and knowledge filters and that you have absolutely no control of ... (from transcriptions)

This short transcription concerns the power to construct categories ("I have chosen you because ...."), but also how this is a contingent power. Eva said that she had chosen a Chinese person, but she did not want that Chinese person to represent anyone else than her-/himself. This statement indicates that she can never be sure of whether the Chinese person understands her-/himself as representing anyone else, or if s/he acts as a representative for anyone else. This can be understood as a way for participants who are categorized to resist and transgress the categories imposed on them. Karin responded by talking about how persons presumably representing others can only speak for others based on what they believe about others, that is, based on prejudices and limited knowledge. This is yet another aspect of the (im)possibilities to correctly represent others, that these practitioners have to deal with. Consequently, the practitioners cannot know whether the participants in their development projects in their own views represent themselves or others, and if participants in their own views represent others, they do so based on prejudices and limited knowledge.

The issue of production of categories was mentioned at several occasions, indicating an awareness of the problematic. No one specifically mentioned the word power, but since practices for selecting participants was discussed, and the consequences of these practices for representational problems, power was still an issue.

\subsection{The Issue of Invisible or Excluded Subjects}

The issue of whether someone is left out or forgotten - that is, those that are excluded by the existing categories - is rather invisible in the material; we could only find one instance of this. This example comes from common discussions (based on the notes), in which one of the groups brought up focus groups as a possibility to find and include minorities. It was not specified whom the term minorities might refer to, and this indicates that they were aware of the existence of minorities that might not be included. The example is not entirely self-evident, but it is what comes closest to the existence of individuals who live outside of existing categories.

\section{Discussion}

The objective with this paper was to explore representation through the analysis of practitioners' talk about demands driven development. The practitioners were discussing how they work with representation in their development projects, and how they sometimes only had very few participants - as few as one - and were happy about this. Despite this they also discussed in a rather sophisticated way the problems with representational practices. In other words the practitioners seemed to agree with Butler [2] and Barad [1] about the problematic with representational practices; but 
nevertheless they seemed to keep on working with representational practices in their development projects. Our empirical material gives no indications as to the reasons for this, but clues to the reasons for this situation may be found elsewhere. One reason is probably the dominant position of representationalism in our society [1]. Representationalist practices are everywhere; in everyday linguistic practices words are taken to correspond to objects, subjects or some aspect of reality. In research and knowledge making individuals are regularly classified into women and men, upper, middle and working class, Swedes and immigrants, living in rural or urban areas, various groups based on age, or employed and unemployed, and studied and described based on these classifications. And in representational politics politicians are expected to speak for (or represent) various interests or perspectives. These representational practices are an important, routinized and taken for granted part of our everyday lives. Representationalism and its individualist foundation is not only an understanding of the relation between reality, knowledge and humans, but it is regularly produced and reproduced in these and other practices, of which the practitioners' work with demands driven development are part.

There also seems to be a lack of alternatives to representational practices - or are there alternatives? Barad [1] discuss how representationalism did not always hold this dominant position, and how there are alternatives. It might be that the alternatives are made invisible, because current state of affairs serves central interests, and because influential actors gain some sort of advantage. Representational practices is common in political systems such as representational democracies, but also in numerous statistical practices $[13,6]$ - in research, marketing, surveys, and the production of government statistics - which categorize individuals and then describe them based on these categorizations. Additionally representationalism is an integral part of positivist research practices in which subjects and objects of study are presumed to exist as stable and autonomous phenomena, independent of researchers and research practices $[17,11,1]$. Positivist research practices are closely linked to natural and technological sciences such as mathematics, physics, chemistry, biology, engineering science and medical science; sciences which are and have been important for creating the wealth and socioeconomic welfare of current industrialized countries [11]. Taken together, these are deeply institutionalized sociomaterial practices which take place in several different areas of society, and which are not that easy to change, because they are an integral part of how our society works, and quite a lot of individuals make their livelihood from the organizations, companies and institutions that are involved in these practices.

\section{References}

1. Barad, K.: Meeting the Universe Halfway. Quantum physics and the entanglement of matter and meaning. Duke University Press, Durham \& London (2007)

2. Butler, J.: Gender Trouble. Feminism and the Subversion of Identity. Routledge, New York \& London (1990)

3. Butler, J.: Bodies that Matter. On the Discursive Limits of "Sex". Routledge, New York \& London (1993) 
4. The European eGovernment Action Plan 2011-2015

5. E-Delegationen: Vägledning för behovsdriven utveckling (Guidelines for demands driven development) (2012)

6. Edling, C., Hedström, P.: Kvantitativa metoder. Grundläggande analysmetoder för samhälls- och beteendevetare (Quantitative methods. Basic analytic methods for social and behavioral scientists). Studentlitteratur, Lund (2003)

7. Essers, C., Benschop, Y.: Muslim businesswomen doing boundary work: The negotiations of Islam, gender and ethnicity within entrepreneurial contexts. Human Relations 62(3), 403-423 (2009)

8. Foucault, M.: The Will to Knowledge. History of Sexuality, vol. 1. Penguin Books, London (1976)

9. Frith, K., Shaw, P., Cheng, H.: The Construction of Beauty: A Cross-Cultural Analysis of Women's Magazine Advertising. Journal of Communication 55(1), 56-70 (2005)

10. Haraway, D.: Cyborgs, Coyotes, and Dogs: A Kinship of Feminist Figurations and There are lways More Things Going on Than You Thoghts! Methodologies as Thinking Technologies. An interview with Donna Haraway Conducted in two parts by Nina Lykke, Randi Markussen, and Finn Olesen. In: Haraway, D. (ed.) The Haraway Reader. Routledge, New York \& London (2000)

11. Harding, S.: Sciences from Below. Feminisms, Postcolonialities, and Modernities. Duke University Press, Durham and London (2008)

12. Karlsson, M.: Democratic Legitimacy and Recruitment Strategies in eParticipation Projects. In: Charalabidis, Y., Koussouris, S. (eds.) Empowering Open and Collaborative Government: Tehcnologies and Methods for On-line Citizen Engagement in Public Policy Making. Springer, Heidelberg (2011)

13. King, G., Keohane, R.O., Verba, S.: Designing Social Inquiry. Scientific Inference in Qualitative Research. Princeton University Press, Princeton (1994)

14. Lindblad-Gidlund, K.: Behovsdriven utveckling av offentliga e-tjänster - Samverkan kring utmaningar och möjligheter (Demands driven development of public e-services - Cooperation around challenges and possibilities). Project report, Mid Sweden University, Sundsvall (2012)

15. Ministerial Declaration on eGovernment (2009)

16. Nikander, P.: Doing change and continuity: age identity and the micro-macro divide. Ageing and Society 29(06), 863-881 (2009)

17. Orlikowski, W.J., Baroudi, J.J.: Studying Information Technology in Organizations: Research Approaches and Assumptions. Information Systems Research 2(1), 1-28 (1991)

18. Pruitt, J., Grudin, J.: Personas: Practice and Theory. In: Proceedings of the 2003 Conference on Designing for User Experiences, pp. 1-15. ACM (2003)

19. Trautner, M.N.: Doing Gender, Doing Class: The Performance of Sexuality in Exotic Dance Clubs. Gender and Society 19(6), 771-788 (2005)

20. Universitets- och högskolerådet, http: / / www . programkontoret.se 